Preface

\title{
Emergent Paradigms of Thrombosis and Cancer (Part II): More on Thrombosis and Cancer
}

\author{
Hau C. Kwaan, MD, FRCP ${ }^{1}$ Paul F. Lindholm, MD² \\ ${ }^{1}$ Division of Hematology/Oncology, Feinberg School of Medicine, \\ Northwestern University, Chicago, Illinois \\ ${ }^{2}$ Department of Pathology, Feinberg School of Medicine, \\ Northwestern University, Chicago, Illinois
}

Semin Thromb Hemost 2019;45:557-558.

In a recent issue of this journal, ${ }^{1}$ we presented to our readership a series of articles on the interaction between thrombosis and cancer. We are continuing in this issue to provide more articles on this theme. The thrombogenic activity of cancer contributes to the increased incidence of thrombosis in cancer patients, while the advent of thrombosis in a cancer patient increases mortality, thrombosis being the second most common cause of death in cancer.

This interrelationship is complex and is gaining recognition with recent findings based on (1) thrombogenic factors produced by cancer cells, as well as by the comorbid conditions, in the cancer patient and (2) the many factors in thrombosis that can activate pathways leading to tumorigenesis, proliferation, and metastasis (-Fig. 1). As illustrated, in thrombosis, the activation of the coagulation cascade triggers tissue factor activation, followed by formation of tissue factor-Factor VIIa-Factor Xa complex, leading to thrombin generation and fibrin formation. The tissue factor-factor VIla-Factor Xa complex can proteolyze protease activated receptor 1 (PAR1 ) and protease activated receptor 2 (PAR-2). These receptors (PAR-1 and -2) can signal growth factor pathways, such as transforming growth factor- $\beta$ (TGF- $\beta$ ), which can promote the epithelial-to-mesenchymal transition, as well as angiogenesis. These pathways are reviewed in detail by Sharma and colleagues. $^{2}$

Another event in thrombosis is the activation of platelets. Both activated platelets and platelet microparticles release angiogenic factors, including vascular endothelial growth factor (VEGF), $\beta$ fibroblast growth factor ( $\beta$-FGF), platelet derived growth factor (PDGF), epidermal growth factor (EGF), insulin growth factor 1 (IGF-1), and the cytokines interleukin 6 and 8 (IL-6 and IL-8), chemokines regulated upon activation normal T-cell expressed and secreted (RANTES), angiopoietins 1, 2, and 4, and matrix metalloproteinases (MMP-1, MMP-2, and MMP-9). The role of these factors are discussed by Mège et al. $^{3}$ They also review how tumor cells activate platelets through coagulation proteins,

Address for correspondence Hau C. Kwaan, MD, FRCP, Division of Hematology/Oncology, Feinberg School of Medicine, Northwestern University, Chicago, IL (e-mail: h-kwaan@ northwestern.edu). such as tissue factor, and adhesive proteins such as P-selectin and podoplanin.

The role of vascular permeability and fibrin deposition is described by Dvorak ${ }^{4}$ who postulates from this mechanism that cancer derives from "the wound that does not heal."

A useful way to study thrombogenic, as well as tumorigenic, factors is that of microparticles in the blood of cancer patients, as summarized by LaCroix and colleagues. ${ }^{5}$ These tumor cell derived microparticles, carry with them both coagulation and fibrinolytic factors, and circulate through blood to the rest of the body.

In myeloproliferative neoplasms, mutations in hematopoietic cells leads to increased risk of thromboembolism, as presented by Arachchillage and Laffan. ${ }^{6}$ In acute promyelocytic leukemia, the arising hemostatic dysfunction results in increased bleeding and thrombotic complications. Such complications, especially intracranial hemorrhage, account for the most common cause of morbidity and mortality in this disease. Tissue factor and fibrinolytic components are produced by the leukemic promyelocytes, leading to a thrombohemorrhagic syndrome. Such unique hemostatic dysfunction is described by Kwaan et al. ${ }^{7}$

The remaining articles are devoted to therapy, with review of various anticoagulant attempts to control cancer by Nadir, ${ }^{8}$ who discusses that inhibiting coagulation to ameliorate cancer was met with disappointing results in clinical trials. The use of anticoagulants in cancer-associated thrombosis is not without risk, as discussed by Park and Khorana, ${ }^{9}$ while the benefits of the direct oral anticoagulants for the treatment of thrombosis in cancer patients are described by Suryanarayan et al. ${ }^{10}$

Finally, the common use of blood transfusion for the cancer patient is not without complications. Notably, there is an association between transfusion and thrombosis, as presented by Ramsey and Lindholm. ${ }^{11}$

We hope our readers will enjoy this issue as much as they did the first on Thrombosis and Cancer. ${ }^{1}$
Copyright $\odot 2019$ by Thieme Medical Publishers, Inc., 333 Seventh Avenue, New York, NY 10001, USA.

Tel: +1(212) 584-4662.
DOI https://doi.org/ ISSN 0094-6176. 10.1055/s-0039-1694764.
Hau C. Kwaan, MD, PhD, and Pau

F. Lindholm, MD. 


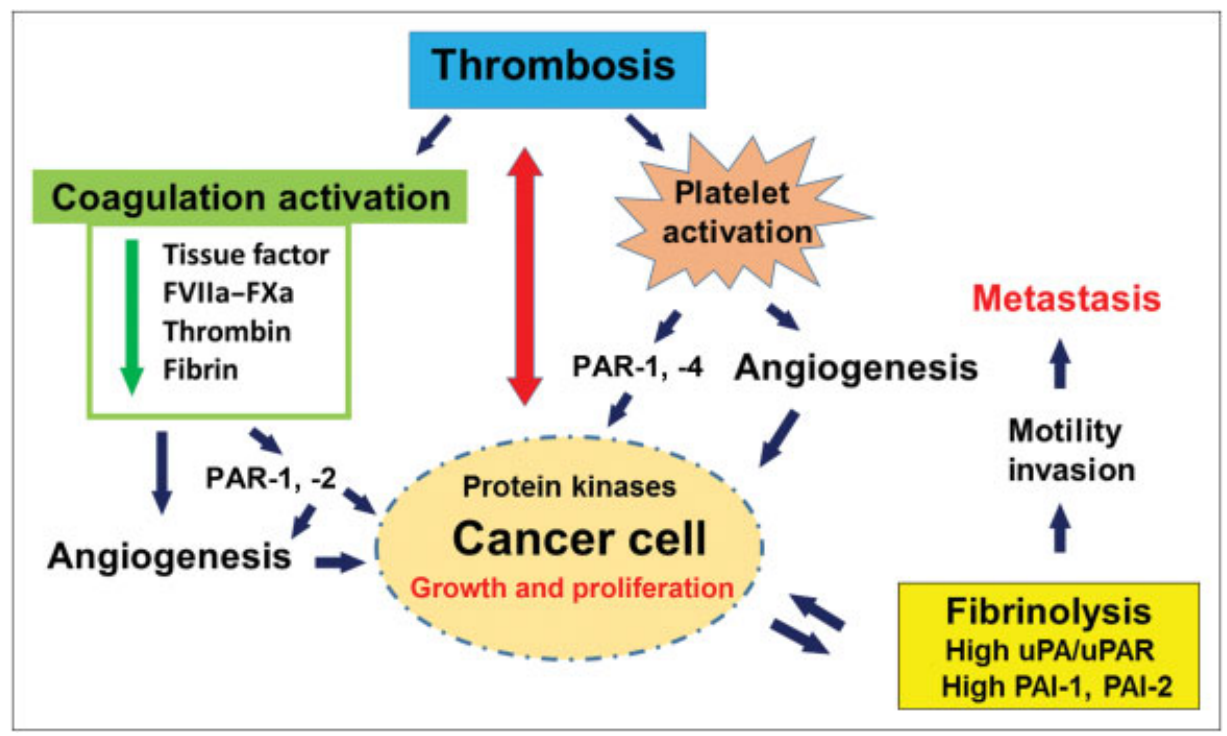

Fig. 1 A simplified version of the interrelationship between thrombosis and cancer. Activation of coagulation factors leads to formation of activated tissue factor, generation of factor VIla and factor Xa (FVlla-FXa) complex, thrombin, and fibrin formation. These factors activate protease-activated receptor 1 (PAR-1) and protease-activated receptor 2 (PAR-2) on cancer cells to promote cancer cell growth, proliferation, angiogenesis, and metastasis. Platelet activation in thrombosis also activates PAR-1 and PAR-4. In addition, fibrinolytic components, urokinase-type plasminogen activator (uPA), uPA receptor (UPAR), and plasminogen activator inhibitor 1 (PAl-1) and plasminogen activator inhibitor 2 (PAl-2) are increased in cancer cells, signifying poor prognosis, but they also enhance cancer cell growth, proliferation, motility, invasion, and metastasis.

\section{Conflict of Interest}

None declared.

\section{References}

1 Kwaan HC, Lindholm PF. Emergent paradigms of thrombosis and cancer (part I): the yin yang relationship between thrombosis and cancer. Semin Thromb Hemost 2019;45(04): 319-320

2 Sharma BK, Flick MJ, Palumbo JS. Cancer-associated thrombosis: a two-way street. Semin Thromb Hemost 2019;45(06): 559-568

3 Mege D, Aubert M, Lacroix R, Dignat-George F, Panicot-Dubois L, Dubois C. Involvement of platelets in cancers. Semin Thromb Hemost 2019;45(06):569-575

4 Dvorak HF. Tumors: wounds that do not heal-a historical perspective with a focus of the fundamental roles of increased vascular permeability and clotting. Semin Thromb Hemost 2019;45(06):576-592
5 Lacroix R, Vallier L, Bonifay A, et al. Microvesicles and cancer associated thrombosis. Semin Thromb Hemost 2019;45(06):593-603

6 Arachchillage DRJ, Laffan M. Pathogenesis and management of thrombotic disease in myeloproliferative neoplasms. Semin Thromb Hemost 2019;45(06):604-611

7 Kwaan HC, Weiss I, Tallman MS. The role of abnormal hemostasis and fibrinolysis in morbidity and mortality of acute promyelocytic leukemia. Semin Thromb Hemost 2019;45(06):612-621

8 Nadir Y. Decrease in tumor growth and angiogenesis mediated by coagulation inhibition. Semin Thromb Hemost 2019;45(06): 622-628

9 Park DY, Khorana AA. Risks and benefits of anticoagulation in cancer and non-cancer patients. Semin Thromb Hemost 2019; 45(06):629-637

10 Suryanarayan D, Lee AYY, Wu C. Direct oral anticoagulants in cancer patients. Semin Thromb Hemost 2019;45(06):638-647

11 Ramsey G, Lindholm PF. Thrombosis risk in cancer patients receiving red cell transfusions. Semin Thromb Hemost 2019; 45(06):648-656 